\title{
INVESTIGATION OF THE OCCURRENCE OF PESTICIDE RESIDUES IN RURAL WELLS AND SURFACE WATER FOLLOWING APPLICATION TO TOBACCO
}

\author{
Edson C. Bortoluzzi \\ Faculdade de Agronomia e Medicina Veterinária, Universidade de Passo Fundo, Campus I, 99001-970 Passo Fundo - RS, Brazil \\ Danilo S. Rheinheimer, Celso S. Gonçalves and João B. R. Pellegrini \\ Departamento de Solos, Universidade Federal de Santa Maria, 97105-900 Santa Maria - RS, Brazil \\ Aline M. Maroneze, Márcia H. S. Kurz, Nádia M. Bacar and Renato Zanella* \\ Departamento de Química, Universidade Federal de Santa Maria, 97105-900 Santa Maria - RS, Brazil
}

Recebido em 25/9/06; aceito em 4/5/07; publicado na web em 25/10/07

\begin{abstract}
In this work the exposure of wells and surface water to pesticides, commonly used for tobacco cropping, was assessed. Water consumption wells and surface water flows were sampled at different times. After a preconcentration step with solid phase extraction (SPE), the selected pesticides were determined by gas chromatography with electron capture detection (GC-ECD) or high performance liquid chromatography with diode array detection (HPLC-DAD). No pesticides were detected in the well water samples and surface water flow in the winter season. However, in the spring and summer higher concentrations of chlorpyrifos and imidacloprid were found in the water source samples. Atrazine, simazine and clomazone were also found. The occurrence of pesticides in collected water samples was related with the application to tobacco.
\end{abstract}

Keywords: water analysis; GC-ECD; HPLC-DAD.

\section{INTRODUCTION}

The use of ground water in or adjacent to agricultural land requires special consideration, particularly in rural areas where it may be used for domestic supply. Pollution of water sources by pesticides is a topic of current international concern. Pesticide runoff pollutes ground and surface waters, which threatens the safety of our aquatic environments and drinking water supplies. Streams and rivers commonly contain detectable concentrations of one or more pesticides, and many of these streams are used for public water supply or flow into reservoirs used to supply drinking water. Pesticides guarantee high production levels and quality standards, but they are also partially released to the atmosphere and hydrosphere of agroecosystems ${ }^{1}$. The lack of strategies for soil and water protection and the incorrect use of management practices produce a great pollutant quantity and, by consequence, a diffuse pollution process ${ }^{2}$. The direct discharge of pesticide packaging in the environment is also a factor, which cannot be ignored. The quality of surface water has been studied in rural areas because it can be influenced by human activity and can affect human health ${ }^{3}$. In a lot Brazilian rural zones, the water sources do not receive any treatment against biological, physical and chemical agents. In contrast, several pesticide types are used as prophylactic treatments against insects, weeds and fungus, in order to engender harmful effects in plants. These pesticides interact with the air, soil and water, causing serious environmental pollution. The line between prophylactic actions and the pollution process is thereby tenuous. The amount of pesticide that is transferred from terrestrial to aquatic systems depends on local factors, as such soil characteristics and climatic conditions ${ }^{4}$. The soluble compounds are easily transferred to the water flow and certain molecules are adsorbed on mineral and organic constituents of the soil ${ }^{5,6}$. Related agricultural chemicals (pesticides and fertilizers) are considered to be the main input to

*e-mail: rzanella@base.ufsm.br water quality problems ${ }^{7}$. Gonzales-Pradas et al. ${ }^{8}$ reported that residues of the insecticide imidacloprid reach a great soil depth because of transport by organic molecule vectors. However, Barriuso et al. ${ }^{1}$ reported that only $1 \%$ of the total of pesticides applied in the fields reach fluvial waters. This is because many processes, such as evaporation, adsorption, diffusion, leaching, photodecomposition and biological degradation influence the presence of pesticides in the environment ${ }^{9}$. Rawn et al. ${ }^{10}$ observed that the herbicide concentration in surface water reflected local application times.

In general, the drainage basins in the state of Rio Grande do Sul - Brazil are occupied by small farmers, who practice intensive agriculture on susceptible areas, i.e. areas with steep and areas with active erosion processes. These conditions are favorable for soil and water pollution ${ }^{11}$. Many tobacco producers live in rural areas near where they and other producers grow tobacco, therefore, their personal water supply is susceptible to pollution. The vulnerability to contamination of streams and ground water can differ seasonally. This must be characterized and understood for each watershed because they dictate the season of the highest pesticide concentrations in drinking water supplies ${ }^{1}$.

In Brazil, research on pesticide leaching from agricultural areas to groundwater was initiated years ago, but knowledge of the levels of contamination of groundwater is still very scarce in several areas ${ }^{12}$. Groundwater vulnerability mapping is an essential component for the design of aquifer protection and management strategies. In developing countries it is of the utmost importance to make use of mapping approaches to support decision-making with respect to the vulnerability of groundwater pollution, especially by organic compounds ${ }^{13}$.

In the present study a temporal trend of some pesticides in drinking-water sources, i.e. sources of consumption and surface water flow, investigating the presence of pesticide residues was established in order to diagnose and understand the process of transfer of pesticides throughout a drainage basin after application to tobacco. The selected pesticides, after a preconcentration step using solid 
phase extraction (SPE), were determined by gas chromatography with electron capture detection (GC-ECD) and by high performance liquid chromatography with diode array detection (HPLC-DAD).

\section{EXPERIMENTAL}

\section{Sites characterization and location}

The three drainage basins studied are located in the state of Rio Grande do Sul, the most southern state of Brazil. The Nova Boemia basin with an area of $5.72 \mathrm{~km}^{2}$ on basaltic rock formations is located in the municipality of Agudo and flows into Jacuí River. Cândido Brum basin with an area of $1.33 \mathrm{~km}^{2}$ over basaltic rock formations is located in the municipality of Arvorezinha and flows into the Guaporé River. The Passo do Meio basin with an area of $10.38 \mathrm{~km}^{2}$ over granite is located in the municipality of Cristal and flows into the Camaquã River.

In general, the original vegetation is predominantly forest. In these drainage basins, the soils are young and generally not deep and have a good natural drainage system. The climate is subtropical humid, with annual mean of $1700 \mathrm{~mm}$ of rainfall and the mean temperature of $19{ }^{\circ} \mathrm{C}$. Relieves have a steep slope of more than $15 \%$. The area is occupied by small farmers (with an average of 10 hectares each). Due to a great demand for tobacco an extensive workload is necessary. In these regions it is the principal crop cultivated in the spring and summer seasons, although, in some cases, maize is cultivated after tobacco.

\section{Water sampling}

Water samples were collected from four wells used for human consumption and four points of drainage channels or creeks in each one of the three drainage basins. The samples were collected five times between 2001 and 2002. The channels serve as water overland runoff drains. The water samples collected at these sites are defined as surface water flow (SWF). The sampling points of the channels were always the same. The sampling apparatus used was a risingstage sampler ${ }^{14}$.

The first sampling was in July 2001, during the winter season. There was little spontaneous vegetation covering the soil. The second sampling was from July to August 2001, during the soil tillage period. The third sampling was after the tobacco seedling transplantation to the field, in October 2001. The fourth sampling was done during plant growth (6-10 leaves) in November 2001. The fifth sampling was done when the plants apexes were removed, from December 2001 to January 2002. The samples were conditioned in amber glass recipients of one liter capacity with aluminum lined caps. These recipients were previously cleaned and sterilized with alkaline Extran ${ }^{\hat{a}}$, rinsed with methanol and dried in an oven at $105^{\circ} \mathrm{C}$. The samples were transported from the field to the laboratories under refrigeration (ca. $10{ }^{\circ} \mathrm{C}$ ), where they were prepared for the chromatographic analyses.

\section{Chemicals and reagents}

The pesticide standards were obtained from Dr. Ehrenstorfer GmbH (Augsburg, Germany). The water was purified with a Milli$\mathrm{Q}^{\circledR}$ water purification system (Millipore Bedford, MA, USA). Methanol of chromatographic grade was obtained from Mallinckrodt (Phillipsburg, NJ, USA). Phosphoric acid of analytical grade was obtained from Merck (Darmstadt, Germany). The solid phase extraction (SPE) cartridges were Strata $\mathrm{C}_{18}$ (size $3 \mathrm{~mL}, 500 \mathrm{mg}$ ) from Phenomenex (Torrance, CA, USA).

\section{Instruments}

The HPLC-DAD system consisted of a Varian (Walnut Creek, CA, USA) Model Star 9010 pump equipped with a 7125 Rheodyne (Cotati, CA, USA) six-port valve with a $20 \mu \mathrm{L}$ loop, and a Varian ProStar 335 diode array detector. The analytical column was a Bondesil C18 (250 x $4.6 \mathrm{~mm}$ i.d.; $5 \mu \mathrm{m})$ from Varian.

The GC-ECD system was a Varian Model 3800 equipped with electron capture detector, autosampler 8200 and a DB-5 fused-silica capillary column (30 m x $0.25 \mathrm{~mm}$ i.d., $0.25 \mu \mathrm{m}$ film thickness; J \& W Scientific, Folsom, CA, USA). The software Star Workstation 6.2 from Varian was used for data acquisition in both systems.

\section{Procedure}

Before sample application, the SPE cartridges were conditioned by consecutively passing $3 \mathrm{~mL}$ of the solvent used for the elution step and $6 \mathrm{~mL}$ of Milli-Q water at $\mathrm{pH}$ 3.0. The water samples, after adjusting the $\mathrm{pH}$ to 3.0 with phosphoric acid, were mixed well and a volume of $100 \mathrm{~mL}$ was passed through the SPE column at $10 \mathrm{~mL}$ $\mathrm{min}^{-1}$. After that, the column was eluted with $1.5 \mathrm{~mL}$ (3 aliquots of $500 \mu \mathrm{L}$ ) of methanol for HPLC-DAD analysis or with ethyl acetate for GC-ECD analysis. The methanol was evaporated to dryness under a gentle stream of nitrogen and the residue redissolved in $0.5 \mathrm{~mL}$ of methanol. For ethyl acetate this step was not necessary.

For the HPLC-DAD analysis, the mobile phase was methanolwater $(55: 45 ; \mathrm{v} / \mathrm{v})$ adjusted to $\mathrm{pH} 3.0$ with phosphoric acid and the pesticides were detected at $220 \mathrm{~nm}$. The GC-ECD used the 1079 injector with splitless injection of $1 \mu \mathrm{L}$ at $270{ }^{\circ} \mathrm{C}$. The ECD detector was maintained at $300{ }^{\circ} \mathrm{C}$, with the make-up gas nitrogen flowrates at $30.0 \mathrm{~mL} \mathrm{~min}{ }^{-1}$. The oven temperature program was $80{ }^{\circ} \mathrm{C}$ for $2 \mathrm{~min}$, ramped to $290{ }^{\circ} \mathrm{C}$ at $15^{\circ} \mathrm{C} \mathrm{min}{ }^{-1}$, maintained for $1 \mathrm{~min}$. The carrier gas was helium at a head pressure of $18 \mathrm{psi}$.

The pesticides commonly used in the tobacco crop were analyzed in the water samples. The chlorpyrifos, flumetralin e iprodione were analyzed by GC-ECD. The imidacloprid, atrazine, simazine e clomazone were analyzed by HPLC-DAD.

\section{RESULTS AND DISCUSSION}

The obtained limits of detection in surface water were $0.05 \mu \mathrm{g}$ $\mathrm{L}^{-1}$ for chlorpyrifos, flumetralin and imidacloprid; $10 \mu \mathrm{g} \mathrm{L}^{-1}$ for iprodione; $0.1 \mu \mathrm{g} \mathrm{L}^{-1}$ for atrazine and simazine and, $0.2 \mu \mathrm{g} \mathrm{L}^{-1}$ for clomazone.

Considering the three investigated drainage basins, no pesticides were detected in the samples collected from the $1^{\text {st }}$ and $2^{\text {nd }}$ sampling, during the winter season and during the soil tillage, respectively. In contrast, chlorpyrifos, imidacloprid, atrazine, simazine, and clomazone were detected one or more times during the crop season in samples taken from the wells and the surface water flow (SWF). However, flumetralin and iprodione pesticides were not detected in the water samples.

Chlorpyrifos, imidacloprid, atrazine, and simazine were found in the Agudo basin in the wells and/or the SWF (Table 1). Chlorpyrifos and imidacloprid were found in the samples collected from the third sampling, during the tobacco seedling transplantation. Chlorpyrifos was found in $75 \%$ of well samples with a mean concentration of $0.09 \mu \mathrm{g} \mathrm{L}^{-1}$ and only in one SWF sample, where the concentration was $0.07 \mu \mathrm{g} \mathrm{L}^{-1}$. The imidacloprid was found in $50 \%$ of the well water samples with a mean concentration of 4.53 $\mu \mathrm{g} \mathrm{L}^{-1}$ and in one SWF sample, with $0.66 \mu \mathrm{g} \mathrm{L}^{-1}$. At the fourth sampling date, all well samples contained the chlorpyrifos pesticide, 
at a mean concentration of $0.11 \mu \mathrm{g} \mathrm{L}^{-1}$. In the SWF samples, $75 \%$ presented this pesticide. From the same samples, pesticides such as imidacloprid, atrazine and simazine were found in only one well and atrazine was found in only one SWF sample.

In the Arvorezinha basin, chlorpyrifos, imidacloprid, atrazine, and clomazone were detected in both well and SWF samples (Table 2). At the third sampling, during the tobacco seedling transplantation, chlorpyrifos and imidacloprid pesticides were found in the well and SWF samples. All these samples presented chlorpyrifos, which was found at a mean concentration of 0.13 and $0.18 \mu \mathrm{g} \mathrm{L}^{-1}$, respectively. At the fourth sampling time, when the plants were with 6 to 10 leaves, chlorpyrifos was not detected in samples from wells, although it was found in one SWF sample. In contrast, the imidacloprid pesticide was found in $100 \%$ of well samples, at a mean concentration of $1.34 \mu \mathrm{g} \mathrm{L}^{-1}$ and in one SWF sample. Atrazine was detected in one well and in one SWF sample. The clomazone was detected in $50 \%$ of well and SWF samples, at a mean concentration of 6.76 and $9.45 \mu \mathrm{g} \mathrm{L}^{-1}$, respectively. No pesticides were found in the samples collected at the last tobacco crop stage.

Chlorpyrifos, imidacloprid, and atrazine were found in some well and SWF samples collected at the Cristal basin (Table 3). At the samples obtained during tobacco seedling transplantation only chlorpyrifos was found. In the well samples, this pesticide was found in $75 \%$ of samples, at a mean concentration of $0.19 \mu \mathrm{g} \mathrm{\textrm {L } ^ { - 1 }}$. In the SWF samples this pesticide was found in $50 \%$ of samples, at a mean concentration of $0.13 \mu \mathrm{g} \mathrm{L}^{-1}$. At the 6 to 10 leaves stage, there was no chlorpyrifos in the well samples. In contrast, this pesticide was found in $50 \%$ of SWF samples. Imidacloprid and atrazine were found in $50 \%$ of the well water samples, at a mean concentration of 1.88 and $0.31 \mu \mathrm{g} \mathrm{L}{ }^{-1}$, respectively. In the SWF samples, imidacloprid and atrazine were found in $75 \%$ (at a mean concentration of $1.35 \mu \mathrm{g}$ $\mathrm{L}^{-1}$ ) and in $25 \%$ of samples (at a concentration of $0.13 \mu \mathrm{g} \mathrm{L}^{-1}$ ), respectively.

At the fifth sampling time, pesticides were not found in either well or SWF samples, except chlorpyrifos, which was found in one SWF sample in the Agudo basin, at a concentration of $0.19 \mu \mathrm{g} \mathrm{L}^{-1}$.

Pesticides found in water samples collected from the studied drainage basins are closely related to the growth season (spring and summer season). This is due to fact that the tobacco crop is cultivated during the spring season, which requires intense fertilization and pesticide treatments, as a function of leave quality. Furthermore, the surface soil conditions, such as low soil coverage, high soil slope

Table 1. Pesticide concentration in well and surface water flow samples, collected during the season tobacco crop in Agudo basin - RS, Brazil

\begin{tabular}{|c|c|c|c|c|c|c|c|c|c|c|c|c|}
\hline \multirow[t]{2}{*}{ Pesticide } & \multirow{2}{*}{$\begin{array}{l}\text { Seedling } \\
\mathrm{a}^{1}\end{array}$} & \multicolumn{2}{|c|}{ transplantation } & \multirow{2}{*}{$\begin{array}{l}\text { (Spring) } \\
\quad \mathrm{d}\end{array}$} & \multicolumn{4}{|c|}{$\begin{array}{l}\text { Tobacco crop stage } \\
\text { Plants with } 6 \text { to } 10 \text { leaves (Spring) }\end{array}$} & \multicolumn{4}{|c|}{ Removing plant apex (Summer } \\
\hline & & $\mathrm{b}$ & $\mathrm{c}$ & & a & $\mathrm{b}$ & $\mathrm{c}$ & d & a & $\mathrm{b}$ & $\mathrm{c}$ & d \\
\hline & \multicolumn{12}{|c|}{ Pesticides concentration in wells, $\mu \mathrm{g} \mathrm{L}^{-1}$} \\
\hline Chlorpyrifos & $\mathrm{n} \cdot \mathrm{d}^{2}$ & 0.10 & 0.09 & 0.08 & 0.12 & 0.12 & 0.14 & 0.11 & n.d. & n.d. & n.d. & n.d. \\
\hline Imidacloprid & n.d. & 2.84 & 6.22 & n.d. & n.d. & 0.81 & n.d. & n.d. & n.d. & n.d. & n.d. & n.d. \\
\hline Atrazine & n.d. & n.d. & n.d. & n.d. & n.d. & 0.24 & n.d. & n.d. & n.d. & n.d. & n.d. & n.d. \\
\hline Simazine & n.d. & n.d. & n.d. & n.d. & n.d. & 0.81 & n.d. & n.d. & n.d. & n.d. & n.d. & n.d. \\
\hline \multirow[t]{2}{*}{ Clomazone } & n.d. & n.d. & n.d. & n.d. & n.d. & n.d. & n.d. & n.d. & n.d. & n.d. & n.d. & n.d. \\
\hline & \multicolumn{12}{|c|}{ Pesticides concentration in surface water flow, $\mu \mathrm{g} \mathrm{L^{-1 }}$} \\
\hline Chlorpyrifos & n.d. & 0.08 & n.d. & n.d. & 0.08 & 0.11 & n.d. & 0.13 & n.d. & n.d. & 0.19 & n.d. \\
\hline Imidacloprid & n.d. & 0.66 & n.d. & n.d. & n.d. & n.d. & n.d. & n.d. & n.d. & n.d. & n.d. & n.d. \\
\hline Atrazine & n.d. & n.d. & n.d. & n.d. & n.d. & n.d. & n.d. & 0.48 & n.d. & n.d. & n.d. & n.d. \\
\hline Simazine & n.d. & n.d. & n.d. & n.d. & n.d. & n.d. & n.d. & n.d. & n.d. & n.d. & n.d. & n.d. \\
\hline Clomazone & n.d. & n.d. & n.d. & n.d. & n.d. & n.d. & n.d. & n.d. & n.d. & n.d. & n.d. & n.d. \\
\hline
\end{tabular}

${ }^{1} \mathrm{a}, \mathrm{b}, \mathrm{c}$ and $\mathrm{d}$ are four wells and four SWF sampling points; ${ }^{2}$ n.d.= not detected

Table 2. Pesticide concentration in well and surface water flow samples, collected during the season tobacco crop in Arvorezinha basin - RS, Brazil

\begin{tabular}{|c|c|c|c|c|c|c|c|c|c|c|c|c|}
\hline \multirow[t]{2}{*}{ Pesticide } & \multirow{2}{*}{$\begin{array}{c}\text { Seedling } \\
\mathrm{a}^{1}\end{array}$} & \multicolumn{3}{|c|}{ transplantation (Spring) } & \multicolumn{4}{|c|}{$\begin{array}{c}\text { Tobacco crop stage } \\
\text { Plants with } 6 \text { to } 10 \text { leaves (Spring) }\end{array}$} & \multicolumn{4}{|c|}{ Removing plant apex (Summer } \\
\hline & & $\mathrm{b}$ & $\mathrm{c}$ & $\mathrm{d}$ & $\mathrm{a}$ & $\mathrm{b}$ & $\mathrm{c}$ & $\mathrm{d}$ & $\mathrm{a}$ & $\mathrm{b}$ & $\mathrm{c}$ & $\mathrm{d}$ \\
\hline & \multicolumn{12}{|c|}{ Pesticides concentration in wells, $\mu \mathrm{g} \mathrm{L^{-1 }}$} \\
\hline Chlorpyrifos & 0.13 & 0.11 & 0.14 & 0.15 & n.d. & n.d. & n.d. & n.d. & n.d. & n.d. & n.d. & n.d. \\
\hline Imidacloprid & n.d. ${ }^{2}$ & n.d. & 0.27 & n.d. & 0.67 & 1.57 & 1.47 & 1.66 & n.d. & n.d. & n.d. & n.d. \\
\hline Atrazine & n.d. & n.d. & n.d. & n.d. & n.d. & n.d. & n.d. & 0.69 & n.d. & n.d. & n.d. & n.d. \\
\hline Simazine & n.d. & n.d. & n.d. & n.d. & n.d. & n.d. & n.d. & n.d. & n.d. & n.d. & n.d. & n.d. \\
\hline \multirow[t]{2}{*}{ Clomazone } & n.d. & n.d. & n.d. & n.d. & n.d. & n.d. & 2.68 & 10.84 & n.d. & n.d. & n.d. & n.d. \\
\hline & \multicolumn{12}{|c|}{ Pesticides concentration in surface water flows, $\mu \mathrm{g} \mathrm{L}{ }^{-1}$} \\
\hline Chlorpyrifos & 0.11 & 0.15 & 0.29 & 0.19 & n.d. & n.d. & 0.08 & n.d. & n.d. & n.d. & n.d. & n.d. \\
\hline Imidacloprid & 0.67 & 1.89 & n.d. & n.d. & n.d. & 0.92 & n.d. & n.d. & n.d. & n.d. & n.d. & n.d. \\
\hline Atrazine & n.d. & n.d. & n.d. & n.d. & 0.82 & n.d. & n.d. & n.d. & n.d. & n.d. & n.d. & n.d. \\
\hline Simazine & n.d. & n.d. & n.d. & n.d. & n.d. & n.d. & n.d. & n.d. & n.d. & n.d. & n.d. & n.d. \\
\hline Clomazone & n.d. & n.d. & n.d. & n.d. & 15.69 & n.d. & 3.21 & n.d. & n.d. & n.d. & n.d. & n.d. \\
\hline
\end{tabular}

${ }^{1} \mathrm{a}, \mathrm{b}, \mathrm{c}$ and $\mathrm{d}$ are four wells and four SWF sampling points; ${ }^{2} \mathrm{n} . \mathrm{d} .=$ not detected 
Table 3. Pesticides concentration in well and surface water flow samples, collected during the season tobacco crop in Cristal basin - RS, Brazil

\begin{tabular}{|c|c|c|c|c|c|c|c|c|c|c|c|c|}
\hline \multirow[t]{2}{*}{ Pesticide } & \multirow{2}{*}{$\begin{array}{c}\text { Seedling } \\
\mathrm{a}^{1}\end{array}$} & \multicolumn{3}{|c|}{ transplantation (Spring) } & \multicolumn{4}{|c|}{$\begin{array}{l}\text { Tobacco crop stage } \\
\text { Plants with } 6 \text { to } 10 \text { leaves (Spring) }\end{array}$} & \multirow{2}{*}{$\begin{array}{c}\text { Removing } \\
\text { a }\end{array}$} & \multicolumn{3}{|c|}{ plant apex (Summer) } \\
\hline & & $\mathrm{b}$ & $\mathrm{c}$ & $\mathrm{d}$ & $\mathrm{a}$ & $\mathrm{b}$ & $\mathrm{c}$ & $\mathrm{d}$ & & $\mathrm{b}$ & $\mathrm{c}$ & $\mathrm{d}$ \\
\hline Chlorpyrifos & 0.16 & 0.19 & 0.22 & n.d. & n.d. & n.d. & n.d. & n.d. & n.d. & n.d. & n.d. & n.d. \\
\hline Imidacloprid & n.d. ${ }^{2}$ & n.d. & n.d. & n.d. & 1.44 & 2.33 & n.d. & n.d. & n.d. & n.d. & n.d. & n.d. \\
\hline Atrazine & n.d. & n.d. & n.d. & n.d. & 0.42 & 0.19 & n.d. & n.d. & n.d. & n.d. & n.d. & n.d. \\
\hline \multirow[t]{2}{*}{ Clomazone } & n.d. & n.d. & n.d. & n.d. & n.d. & n.d. & n.d. & n.d. & n.d. & n.d. & n.d. & n.d. \\
\hline & \multicolumn{12}{|c|}{ Pesticides concentration in surface water flows, $\mu \mathrm{g} \mathrm{L}^{-1}$} \\
\hline Chlorpyrifos & 0.16 & 0.11 & n.d. & n.d. & n.d. & 0.06 & 0.07 & n.d. & n.d. & n.d. & n.d. & n.d. \\
\hline Imidacloprid & n.d. & n.d. & n.d. & n.d. & 2.59 & 0.92 & 0.55 & n.d. & n.d. & n.d. & n.d. & n.d. \\
\hline Atrazine & n.d. & n.d. & n.d. & n.d. & n.d. & 0.13 & n.d. & n.d. & n.d. & n.d. & n.d. & n.d. \\
\hline
\end{tabular}

${ }^{1} \mathrm{a}, \mathrm{b}, \mathrm{c}$ and $\mathrm{d}$ are four wells and four SWF sampling points; ${ }^{2}$.d. $=$ not detected

and high amount of rainfall, producing water and sediment loss and transporting a great amount of pollutants, specialty pesticides. Pesticide adsorption on the clay fraction can be a preferential pesticide transfer path to water systems due the erosion ${ }^{15}$. In the Agudo basin the sediment fraction $<2 \mu \mathrm{m}$ is basically composed of smectite clay mineral ${ }^{16}$. This mineral clay depends on the parent material type (basalt and granite rocks) and the genesis of soils. In contrast, during the winter season no pesticide was found in water samples, which coincides with the absence of pesticide applications in this season. It is interesting to note that the pesticide transfer process from the soil to the water occurs quickly, few days after the pesticide application, as in the case of herbicides (Tables 1,2 and 3 ). However, pesticide persistence seems to be low, for most pesticide molecules studied. With the exception of chlorpyrifos, which was found in the three drainage basins studied and in a high number of well and SWF samples, mainly soon after application. However, in the Agudo basin, this pesticide was found at three of the times studied, in all well samples of the second and third sampling and also at several points of SWF during these samplings.

Chlorpyrifos was the pesticide most frequently found in the water samples of the drainage basins studied. Chlorpyrifos has been used largely during tobacco seedling transplantation as a systemic insecticide even though there are other more modern pesticides with lower toxicity. These results are in accordance with Schardein and Scialli ${ }^{17}$, who reported high chlorpyrifos concentrations in the delta of the Mississipi River. Our study shows that chlorpyrifos is persistent four months after the application is discontinued. This is due to the long period of application and possibly to the concentration of chlorpyrifos in the same area, as well to the continuous runoff process commonly found in the studied drainage basin. Although the Brazilian health agency establishes a limit of pollution level for some pesticides, chlorpyrifos and the others investigated pesticides are not included in any such list. Schandein and Scialli ${ }^{17}$ reported that chlorpyrifos has low toxicity in humans. However, these authors alert that the ingestion of water presenting this molecule have higher toxicity in children than in adults. In addition, many of the wells studied in the drainage basins are used for consumption in rural schools.

Imidacloprid was introduced in the tobacco crop in order to reduce the use of other insecticides, such as chlorpyrifos. It is also a systemic insecticide with a long effect since, when applied in the seedling phase, it must protect the plants until the end of their cycle.
Gonzáles-Pradas et $a l .^{8}$ reported that this pesticide has a high mobility in soil profile. However, it was also found in wells and SWF in the studied drainage basins. Since, the tobacco crops in southern Brazil are located near cities, its use should be reviewed in order to decrease the risk of surface water pollution and perhaps that of subterraneous water.

Atrazine, simazine, and clomazone were found in well and SWF samples, mostly at the fourth sampling time. This herbicide group has become more utilized over the last few years because of an increase in the cropped area and a decrease in the manual control of weeds.

The pesticides found in surface water samples, mainly in the wells, demonstrate that there is a pollution problem and subsequently the risk of pesticide contamination in the studied drainage basins. Considering a limit for human consumption in the water of a concentration $0.1 \mu \mathrm{g} \mathrm{L}^{-1}$ for any pesticide and $0.5 \mu \mathrm{g} \mathrm{L}^{-1}$ for a total concentration of pesticides and metabolites established by the European Economic Community (EEC) ${ }^{18}$, we can observe that many water sources analyzed in this work cannot be consumed.

Besides the creation of political measures to reduce the use of pesticides, another important area that should be given attention is the planning. With planning it is possible to make these areas capable to support intensive agriculture with lower risks. The first step towards this end is to reduce the tobacco cropped area located close to water sources and increase permanent vegetation in soil on steep slopes. This action can reduce the erosion process, decreasing surface water losses and changes in the water cycle ${ }^{19}$.

In order to avoid punctual pesticide pollution, the pesticide packaging must be collected at the farms level and should have an adequate destination. Water pollution by pesticides is not only a problem of farmers, but also a problem of the urban community over the long run if the pesticide use continues increasing in crop systems near cities. The research of new molecules with lower toxicity effect and lower soil mobility capacity are also valuable alternatives.

The authors agree to the fact that tobacco is not considered a food, but a plant that demands a high input to be cropped. Actually, it is possible to completely substitute the tobacco crops with other crops with lower risk of soil and water pollution, without causing financial loss to the small farmers.

\section{CONCLUSION}

No pesticides were detected in the wells and surface water loss 
in the winter season. Flumetralin and iprodione were not found in any samples. Higher concentrations of chlorpyrifos and imidacloprid were found in the wells samples destined to human consumption, mainly during tobacco seedling transplant to yield and when the tobacco plants had 6-10 leaves. The herbicides, such as atrazine, simazine, and clomazone were found when the tobacco plants had 6-10 leaves, at the fourth sampling time. The presence of the studied pesticide in collected water is closed related with its use as a prophylactic treatment of tobacco plants. The chlorpyrifos seems to be the more persistent in water among the studied pesticides.

Concern about the harmful effects of pesticides on surface water and groundwater quality should motivate tobacco producers to select pesticides that will have a minimum adverse impact on water quality.

\section{ACKNOWLEDGMENTS}

The authors acknowledge CNPq, CAPES and SAA/RS-RURAL for fellowships and financial support.

\section{REFERENCES}

1. Muller, K.; Bach, M.; Hartmann, H.; Spiteller, M.; Frede, H.-G.; J. Environ. Qual. 2002, 31, 309.

2. Hatfield, J. L.; Water Sci. Technol. 1993, 28, 415.

3. Zanella, R.; Primel, E. G.; Machado, S. L. O.; Gonçalves, F. F.; Marchezan, E.; Chromatographia 2002, 55, 573.
4. Spongberg, A.; Martin-Hayden, J. M.; Environ. Sci. Technol. 1997, 31, 3161.

5. Prost, R.; Yaron, B.; Soil Science 2001, 166, 880.

6. Sheng, G.; Johnston, C. T.; Teppenm, B.; Boyd, S. A.; J. Agric. Food Chem. 2001, 49, 2899

7. Kalita, P. K.; Algoazany, A. S.; Mitchell, J.K.; Cooke, R. A. C.; Hirschi, M. C.; Agric. Ecosyst. Environ. 2006, 115, 183.

8. Gonzáles-Pradas, E.; Ureña-Amate, M. D.; Flores-Céspedes, F.; FernándezPérez, M.; Garratt, J.; Wilkins, R.; Soil Sci. Soc. Am. J. 2003, 66, 1821.

9. Schwarzenbach, R. P.; Gschwend, P. M.; Imboden, D. M.; Environmental organic chemistry, John Wiley \& Sons: New York, 1993.

10. Rawn, D. F. K.; Halldorson, T. H. J.; Turner, W. N.; Woychuk, R. N.; Zakrevsky, J.-G.; Derek, D. C. G.; J. Environ. Qual. 1999, 28, 906.

11. Fiorio, P. R.; Demattê, J. A. M.; Sparocek, G.; Pesq. Agropec. Bras. 2000, 35,671 .

12. Dores, E. F. G. C.; Navickiene, S.; Cunha, M. L. F.; Carbo, L.; Ribeiro, M. L.; De-Lamonica-Freire, E. M.; J. Braz. Chem. Soc. 2006, 17, 866.

13. Mazari-Hiriart, M.; Cruz-Bello, G.; Bojorquez-Tapia, L. A.; JuarezMarusich, L.; Alcantar-Lopez, G.; Marin L. E.; Soto-Galera, E.; Environ. Manage. 2006, 37, 410.

14. Cew-Eh-Y.; Manual Nr. 1110-2-4000, Department of the Army, U.S. Army Corps of Engineers: Washington, 1995.

15. Rostad, C. E.; Leenheer, J. A.; Daniel, S. R.; Environ. Sci. Technol. 1997, 31,3218 .

16. Bortoluzzi, E. C.; Technical repport, Universidade Federal de Santa Maria, CNPq, Brazil, 2004.

17. Schardein, J. L.; Scialli, A. R.; Reprod. Toxicol. 1999, 13, 1.

18. EEC Drinking Water Directive, (80/778/EEC), EEC, 1980 No. L229/11-29.

19. Leu, C.; Singer, H.; Stamm, C.; Mueller, S. R.; Schwarzenbach, R. P.; Environ. Sci. Technol. 2004, 38, 3827. 